Chapman University

Chapman University Digital Commons

Biology, Chemistry, and Environmental Sciences Science and Technology Faculty Articles and Faculty Articles and Research

$1-7-2020$

\title{
Air/Sea Transfer of Highly Soluble Gases Over Coastal Waters
}

J. G. Porter

Warren J. de Bruyn

S. D. Miller

E. S. Saltzman

Follow this and additional works at: https://digitalcommons.chapman.edu/sees_articles

Part of the Atmospheric Sciences Commons, Environmental Chemistry Commons, Oceanography Commons, and the Other Oceanography and Atmospheric Sciences and Meteorology Commons 


\section{Air/Sea Transfer of Highly Soluble Gases Over Coastal Waters}

\section{Comments}

This article was originally published in Geophysical Research Letters, volume 47, in 2020. https://doi.org/ 10.1029/2019GL085286

\section{Copyright}

American Geophysical Union 


\section{Geophysical Research Letters}

\author{
RESEARCH LETTER \\ 10.1029/2019GL085286 \\ Key Points: \\ - Direct flux measurements of sulfur \\ dioxide to the coastal sea surface \\ were made using eddy covariance \\ - Simultaneous measurements of \\ air/sea exchange of sulfur dioxide \\ and water vapor show a difference in \\ air-side resistance likely related to \\ the molecular diffusivities of the two \\ gases \\ - These field measurements can be \\ used to quantify the relative \\ importance of molecular diffusion \\ and turbulence in controlling \\ soluble gas deposition to the sea \\ surface
}

Supporting Information:

- Supporting Information S1

Correspondence to:

E. S. Saltzman,

esaltzma@uci.edu

Citation:

Porter, J. G., de Bruyn, W. J., Miller, S. D., \& Saltzman, E. S. (2020). Air/Sea Transfer of Highly Soluble Gases Over Coastal Waters. Geophysical Research Letters, 47, e2019GL085286. https://doi. org/10.1029/2019GL085286

Received 4 SEP 2019 Accepted 4 JAN 2020

Accepted article online 7 JAN 2020

(C)2020. American Geophysical Union. All Rights Reserved.

\section{Air/Sea Transfer of Highly Soluble Gases Over Coastal Waters}

\author{
J. G. Porter ${ }^{1}$, W. J. de Bruyn ${ }^{2}$, S. D. Miller ${ }^{3}$, and E. S. Saltzman ${ }^{1}$ \\ ${ }^{1}$ Departments of Earth System Science and Chemistry, University of California, Irvine, Irvine, CA, USA, ${ }^{2}$ Department of \\ Chemistry and Biochemistry, Chapman University, Orange, CA, USA, ${ }^{3}$ Atmospheric Sciences Research Center, State \\ University of New York at Albany, Albany, NY, USA
}

\begin{abstract}
The deposition of soluble trace gases to the sea surface is not well studied due to a lack of flux measurements over the ocean. Here we report simultaneous air/sea eddy covariance flux measurements of water vapor, sulfur dioxide $\left(\mathrm{SO}_{2}\right)$, and momentum from a coastal North Atlantic pier. Gas transfer velocities were on average about $20 \%$ lower for $\mathrm{SO}_{2}$ than for $\mathrm{H}_{2} \mathrm{O}$. This difference is attributed to the difference in molecular diffusivity between the two molecules $\left(D_{\mathrm{SO} 2} / D_{\mathrm{H} 2 \mathrm{O}}=0.5\right)$, in reasonable agreement with bulk parameterizations in air/sea gas models. This study demonstrates that it is possible to observe the effect of molecular diffusivity on air-side resistance to gas transfer. The slope of observed relationship between gas transfer velocity and friction velocity is slightly smaller than predicted by gas transfer models, possibly due to wind/wave interactions that are unaccounted for in current models.
\end{abstract}

\section{Introduction}

Research on air/sea exchange of trace gases has focused in recent years primarily on climate-active gases such as carbon dioxide, nitrous oxide, methane, and dimethylsulfide. These gases are moderately to slightly soluble in seawater, and the physical processes controlling resistance to air/sea gas transfer for such gases occur mainly on the ocean side of the interface (Liss \& Slater, 1974). Many highly soluble trace gases are generated by the atmospheric photochemical oxidation of natural and anthropogenic emissions. These include various inorganic acids $\left(\mathrm{HCl}, \mathrm{HNO}_{3}\right.$, and $\left.\mathrm{H}_{2} \mathrm{SO}_{4}\right)$, ammonia, and organic alcohols and acids. Such compounds also play important roles in biogeochemical cycles, climate, and air quality. Atmospheric water vapor, a major component of Earth's energy budget, can also be considered a highly soluble gas.

There have been numerous theoretical and laboratory studies of soluble trace gas deposition to the sea surface, but few field studies (Garratt \& Hicks, 1973; Hicks \& Liss, 1976; Joffre, 1988; Kramm \& Dlugi, 1994; Slinn et al., 1978). Direct flux measurements of soluble trace gases are challenging, due to low ambient concentrations and high reactivity with inlet tubing and other surfaces. The existing database of eddy covariance air/sea flux measurements for such gases consists of limited studies of acetone (Marandino et al., 2005; Yang et al., 2014), methanol (Yang et al., 2013; 2016), and $\mathrm{SO}_{2}$ (Faloona et al., 2009; Porter et al., 2018). $\mathrm{SO}_{2}$ is only moderately soluble but undergoes rapid hydrolysis and ionization in seawater and therefore behaves as a highly soluble gas during air/sea gas transfer (Liss, 1971; Millero et al., 1989; Porter et al., 2018). Deposition of $\mathrm{SO}_{2}$ to the sea surface is a major component of the global sulfur cycle (Sheng et al., 2015).

The air/sea flux of a trace gas is related to the ocean/atmosphere concentration difference and to a gas transfer velocity. The bulk air/sea flux parameterization can be written as follows:

$$
F=k \cdot\left(\frac{C_{w}}{\alpha}-C_{a}\right)
$$

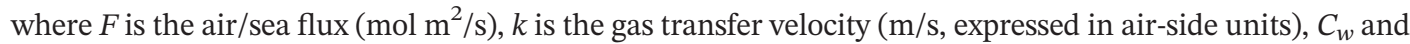
$C_{a}$ are the bulk ocean and air side gas concentrations $\left(\mathrm{mol} / \mathrm{m}^{3}\right)$, and $\alpha$ is the dimensionless solubility (expressed as the ratio of water to air)s. The inverse of the gas transfer velocity, or resistance, $r=1 / \mathrm{k}$ $(\mathrm{s} / \mathrm{m})$, is conceptually useful for assessing the contribution of various physical processes to gas transfer. For highly soluble, air-side controlled gases, resistance occurs predominantly on the atmospheric side of the interface (Liss, 1971; Liss and Slater, 1974). Over the ocean, this resistance arises predominantly from two physical processes, (1) turbulent eddy transport across the atmospheric surface layer, and (2) diffusive 
transport across a thin viscous or interfacial layer adjacent to the surface where turbulence is suppressed. The bulk parameterizations in current use are based on a combination of micrometeorological theory, field observations, and laboratory studies (Duce et al., 1991; Fairall et al., 2000; Johnson, 2010).

There are very few simultaneous observations of air/sea gas exchange for soluble compounds with different molecular diffusivities. Such studies are needed to explore the processes controlling the air-side resistance to gas transfer and to validate bulk parameterizations. Porter et al. (2018) recently reported simultaneous air/sea flux measurements of $\mathrm{SO}_{2}$ and water vapor from Scripps pier and detected systematic differences in transfer velocities for the two gases. They suggested that such differences could be used to quantify the relative importance of diffusive and turbulent transport and gain insight into the air/sea gas transfer process. In this study, we present a more extensive data set comparing gas transfer velocities for $\mathrm{SO}_{2}$ and water vapor from a coastal pier off North Carolina in the North Atlantic Ocean.

\section{Field Site and Methods}

\subsection{Study Site and Experimental Setup}

This study was conducted at the U.S. Army Corps of Engineers Field Research Facility (USACE-FRF) in Duck, North Carolina, from 16 March to 24 April 2015 (DOY 75-114). Field measurements were made from the FRF pier $\left(36^{\circ} 11.04^{\prime} \mathrm{N} 75^{\circ} 44.70^{\prime} \mathrm{W}\right)$. The pier is $560 \mathrm{~m}$ long and oriented perpendicular to the coastline, at a heading of roughly $70^{\circ} \mathrm{E}$. The observations were made at the end of the pier, where the nominal water depth is approximately $7 \mathrm{~m}$ and the tidal range varied from 1-1.5 m over the course of this field study. The sensors and air inlets were mounted on a 3-m-long boom extending seaward from a meteorological tower at the end of the pier. The boom height above the sea surface ranged from 8-10 m depending on the tide.

The parameters measured on the pier included fast response 3-D winds (CSAT3), fast response water vapor (LI-7500), sea surface temperature (thermistor, Apogee SI-111 IR sensor), and atmospheric pressure, temperature, and relative humidity (Vaisala HMP45), whitecaps (by visible imagery), and sea surface height (by ultrasonic sensor) (see Table S1 in the supporting information for details). Wind speed and direction from an anemometer at 19.4-m elevation on the pier tower and SST data from the pier were obtained from the NOAA National Data Buoy Center (Station DUKN7, \#8651370, Duck Pier, NC). Significant wave height was obtained from a Waverider directional buoy at the pier (USACE Gauge ID 630). Continuous real-time measurements of $\mathrm{SO}_{2}$ were made using negative ion chemical ionization mass spectrometry, using a laboratory quadrupole-based instrument described previously (Bell et al., 2013; Porter et al., 2018). A shed located on the end of the pier housed the sulfur dioxide detector, data acquisition electronics, pumps, flow controllers, and clean air generator.

The air intake for $\mathrm{SO}_{2}$ was a 1/4" O.D. Teflon PFA tube fitting attached to a Teflon TFE manifold $(2.5 \times 2.5 \times$ $10 \mathrm{~cm}$ ) where the air stream was combined with an internal standard described below (Dupont Co.). The air intake was located approximately $10 \mathrm{~cm}$ behind the sensing region of the sonic anemometer. The air stream used for $\mathrm{SO}_{2}$ detection was dried at the inlet using two counterflow Nafion membrane driers in series to minimize losses of $\mathrm{SO}_{2}$ to the tubing walls. Air was drawn to the $\mathrm{SO}_{2}$ detector through a 1/4" O.D. PFA Teflon tube, $21 \mathrm{~m}$ in length. $\mathrm{SO}_{2}$ was ionized in the presence of $\mathrm{O}_{3}$ to form the $\mathrm{SO}_{5}{ }^{-}$ion (Möhler et al., 1992; Thornton et al., 2002) during passage of air over a ${ }^{63} \mathrm{Ni}$ beta emitting foil at 430 Torr.

An isotopically labeled ${ }^{34} \mathrm{SO}_{2}$ internal standard was added to the air inlet. Quantification of ambient $\mathrm{SO}_{2}$ was done by simultaneously monitoring the mass spectrometer signals from ${ }^{32} \mathrm{SO}_{5}{ }^{-}$and ${ }^{34} \mathrm{SO}_{5}{ }^{-}, \mathrm{m} / \mathrm{z} 112$ and 114. The internal standard was delivered from a high-pressure aluminum cylinder containing ppm-level ${ }^{34} \mathrm{SO}_{2}$. This internal standard was calibrated in the laboratory against the output of a gravimetrically calibrated $\mathrm{SO}_{2}$ permeation tube. The instrument blank was determined by periodically introducing a carbonate-treated filter to the inlet. Dry air mixing ratios of $\mathrm{SO}_{2}$ were calculated from the measured $\mathrm{m} / \mathrm{z} 112 / 114$ ratio using the procedures described by Porter et al. (2018). The sensitivity of the instrument ranged from 200-250 cps $\mathrm{pmol} / \mathrm{mol} \mathrm{SO}_{2}$. The limit of detection is estimated at $4 \mathrm{pmol} / \mathrm{mol}$.

Analog data from the meteorological sensors and $\mathrm{SO}_{2}$ instrument were recorded at $50 \mathrm{~Hz}$ using a multichannel data logger with a $20-\mathrm{Hz}$ Butterworth filter and LabView software (National Instruments). 


\subsection{Data Processing and Flux Calculations}

Postprocessing of the data was carried out using Matlab (Mathworks). The data were converted to geophysical units and subdivided into 13-min intervals for computing mean quantities, variances, and air-sea fluxes. Winds for each interval were rotated such that the mean vertical and cross-stream winds were zero. Systematic differences in calibration were observed between the LICOR open path water vapor sensor and the Vaisala relative humidity sensor. Data from the two instruments were adjusted to a common (Vaisala) scale by regressing the mean water vapor molar density computed from each sensor. This adjustment ensured that air-sea fluxes and air-sea concentration differences were reported on the same calibration scale. Visible images were processed for whitecap detection using the method of Callaghan and White (2009).

Fluxes of $\mathrm{SO}_{2}$, water vapor and momentum were calculated according to the following equations:

$$
\begin{gathered}
F_{\mathrm{SO} 2}=\overline{w^{\prime} C_{\mathrm{SO}_{2}}^{\prime}}, \\
F_{\mathrm{H}_{2} \mathrm{O}}=\bar{\rho}_{d r y} \overline{w^{\prime} X_{\mathrm{H}_{2} \mathrm{O}}^{\prime}}, \\
F_{m o m}=-\bar{\rho}_{d r y} \overline{w^{\prime} u^{\prime}},
\end{gathered}
$$

where $F$ is flux, primed quantities are fluctuations about the mean, the overbar indicates the time average across a flux interval, $w$ is the vertical wind, $C_{\mathrm{SO} 2}$ is the atmospheric concentration of $\mathrm{SO}_{2}, X_{\mathrm{H}_{2} \mathrm{O}}$ is the mole fraction of water vapor, $\rho_{d r y}$ is the dry air molar density, $u$ is horizontal wind speed, and $\rho$ is air density. A small correction was made to the $\mathrm{SO}_{2}$ fluxes to account for the loss of high-frequency fluctuations in the inlet tubing (Porter et al., 2018). The largest source of uncertainty in the fluxes was covariance on time scales of several minutes. An Ogive method was used to estimate this uncertainty for each flux interval.

The data were quality controlled by eliminating flux intervals with the following characteristics: (1) poor cospectral shape, as determined by comparison to Kaimal et al. (1972), (2) very small bulk air/sea differences of water vapor or $\mathrm{SO}_{2}\left(\Delta \mathrm{X}_{\mathrm{H} 2 \mathrm{O}}<10^{-3} ;<10 \mathrm{pmol} / \mathrm{mol} \mathrm{SO}_{2}\right)$, (3) mean wind directions outside of the sector from $20^{\circ} \mathrm{W}$ to $140^{\circ} \mathrm{E}$ (roughly \pm 90 of the orientation of the pier).

Transfer velocities for flux intervals passing quality control were calculated following equations

$$
\begin{gathered}
k_{\mathrm{SO}_{2}}=\frac{F_{\mathrm{SO}_{2}}}{\bar{\rho}_{d r y} \bar{X}_{\mathrm{SO}_{2}}}, \\
k_{\mathrm{H}_{2} \mathrm{O}}=\frac{F_{\mathrm{H}_{2} \mathrm{O}}}{\bar{X}_{\mathrm{H}_{2} \mathrm{O}}-\bar{X}_{\text {sat }} \bar{\rho}_{d r y}}, \\
k_{\text {mom }}=\frac{F_{\text {mom }}}{\bar{U} \bar{\rho}_{d r y}},
\end{gathered}
$$

where $k$ is transfer velocity, $X_{\text {sat }}$ is mole fraction of water vapor in equilibrium at the sea surface, and $U$ is horizontal wind speed. Uncertainties in $k$ were estimated by propagating the uncertainties in the fluxes and mean quantities.

There is some question as to whether the Kansas-type flux-profile relationships (Kaimal et al., 1972) apply to a coastal environment such as the Duck pier where horizontal heterogeneity is strong and internal boundary layers are prevalent. Grachev et al. (2017) presented an extensive set of meteorological measurements at several levels on the Duck pier tower during 2015. During on-shore flow with an unstable boundary layer, flux-variance relationships were consistent with Monin-Obhukov Similarity Theory (MOST) theory but flux-profile relationships were not. In that study, the lowest levels on the tower may have experienced flow distortion due to the pier itself. In our study, the sensors projected seaward from the pier by $3 \mathrm{~m}$, and the mean vertical angular deflection of the winds was less than $2^{\circ}$ for in-sector winds. Due to the uncertainty in flux-profile relationships, the measured winds were not corrected for the small variations in measurement height associated with tidal change in water depth $( \pm 1 \mathrm{~m})$. 


\section{Results}

\subsection{Meteorological Conditions During the Study}

Climatological winds at the Duck pier during March - May are southeasterly in the $5-10 \mathrm{~m} / \mathrm{s}$ range. The site experiences a local sea breeze circulation with onshore flow during the day and offshore flow at night. Winds at the site are episodically influenced by synoptic scale weather patterns, which typically occur on the time scale of a week. During such events, winds typically shift to a northerly direction, followed by a gradual return to southeasterly flow over several days. Selected time series data from the study are shown in Figures 1 and S1. Wind speeds typically peaked around $15 \mathrm{~m} / \mathrm{s}$ early in frontal events and declined to $5-8 \mathrm{~m} / \mathrm{s}$ as the events ended. Air temperatures declined rapidly during the events from about 20 to $10{ }^{\circ} \mathrm{C}$, typically to within a degree of the sea surface temperature. The conditions encountered during this study are typical of the site, and similar to observations made later in the year (October-November 2015; Grachev et al., 2017). $\mathrm{SO}_{2}$ varied from below detection to above $300 \mathrm{pmol} / \mathrm{mol}$ over the course of the study. $\mathrm{SO}_{2}$ levels were elevated during frontal passages, reflecting transport of continental North American air. $\mathrm{SO}_{2}$ levels were generally below $100 \mathrm{pmol} / \mathrm{mol}$ after frontal passages and during easterly flow.

\subsection{Wind Speed Dependence of Gas Transfer}

Transfer velocities for momentum, water vapor, and sulfur dioxide for Duck pier exhibit a roughly linear dependence on friction velocity $\left(u_{*}\right)$ over a wind speed range from 3-12 m/s (Figure 2). An estimate of the average transfer coefficient, $\left(k / u_{*}\right)^{2}$, for each parameter is provided by the slopes of the linear regressions of $k$ versus $u_{*}$ ( \pm 1 s.e.). These were obtained using the subset of the full Duck data set for which the winds were in-sector and momentum, water vapor, and sulfur dioxide fluxes all passed quality control.

$$
\begin{aligned}
& C_{D}=\left(k_{\text {mom }} / u_{*}\right)^{2}=(1.50 \pm 0.09) \times 10^{-3}, \\
& C_{E}=\left(k_{\mathrm{H}_{2} \mathrm{O}} / u_{*}\right)^{2}=(0.70 \pm 0.05) \times 10^{-3}, \\
& C_{\mathrm{SO}_{2}}=\left(k_{\mathrm{SO}_{2}} / u_{*}\right)^{2}=(0.52 \pm 0.04) \times 10^{-3} .
\end{aligned}
$$

Transfer coefficients for the two gases are significantly smaller than those for momentum. The relative magnitudes of the transfer coefficients $\left(\mathrm{C}_{\mathrm{D}}>>\mathrm{C}_{\mathrm{E}}>\mathrm{C}_{\mathrm{SO} 2}\right)$ is consistent with the physical processes controlling deposition of soluble gases. The transfer of mass at the air/sea interface is limited by the combined resistance due to turbulence (away from the interface itself) and diffusion across the viscous sublayer next to the surface. By contrast, momentum can be transferred to the surface both via viscous stress and by pressure fluctuations for which there is no analog in mass transfer (Liu et al., 1979). For transitional or rough surfaces where form drag is significant, $k_{\text {mom }}$ should always be greater than $k_{\text {gas }}$. At very low wind speeds and smooth water surfaces where viscous stress dominates, one might expect the difference between $k_{\text {mom }}$ and $k_{\text {gas }}$ to decrease. This would be difficult to observe under field conditions because the air/sea fluxes become very small at low wind speeds. In the case of light winds and large swells, wave energy may cause the momentum flux to be upward, while $\mathrm{SO}_{2}$ flux remains downward.

The observed transfer coefficient for water vapor is slightly larger than that for sulfur dioxide $\left(k_{\mathrm{H}_{2} \mathrm{O}}>k_{\mathrm{SO}_{2}}\right)$. The difference between $k_{\mathrm{H}_{2} \mathrm{O}}$ and $k_{\mathrm{SO}_{2}}$ is significant at the $95 \%$ confidence interval. This relationship is expected given that the $\mathrm{H}_{2} \mathrm{O}$ is a smaller molecule than $\mathrm{SO}_{2}$, with a molecular diffusivity in air nearly twice that of $\mathrm{SO}_{2}\left(D_{\mathrm{H}_{2} \mathrm{O}}=0.25 ; D_{\mathrm{SO}_{2}}=0.13 \mathrm{~cm}^{2} / \mathrm{s}\right.$ at $298 \mathrm{~K}$; uncertainty estimated as $\pm 5 \%$; Fuller et al., 1966; Hilsenrath, 1960; Andreas, 2005; Reid et al., 1987).

Physically based bulk gas transfer parameterizations relate the gas transfer velocity (or resistance) to surface stress, which in turn is estimated from observables such as winds, waves, and air and sea surface temperatures. The calculation of surface stress from wind speed involves the calculation of surface roughness using a gravity-wave relationship such as the Charnock model, optimized for open ocean conditions. Such relationships often exhibit biases when compared to data from coastal environments, due to a variety of factors including breaking waves, thermal gradients, currents, fetch, land and ocean bottom topography, and surfactants (Brown et al., 2013; Geernaert et al., 1986; Smith, 1988). In order to compare gas transfer models to the Duck data set, we minimize such biases by using in situ field observations of wind speed and momentum flux to specify friction velocity in the model calculations. 

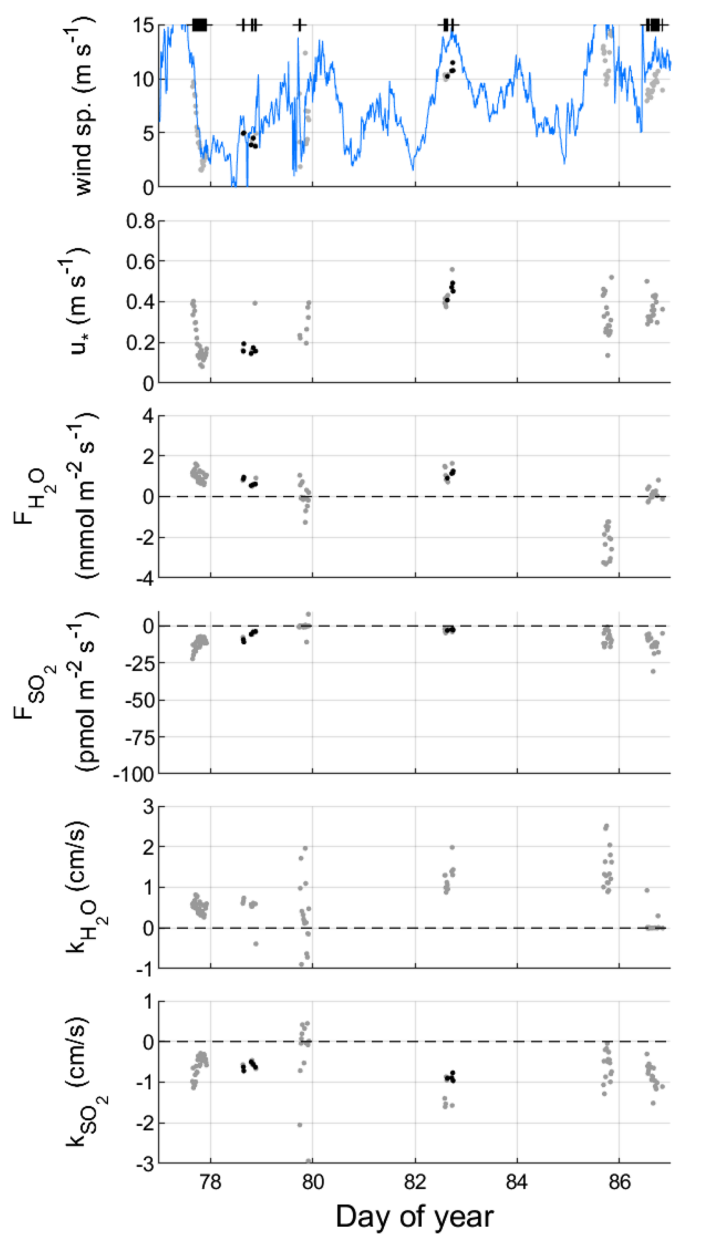
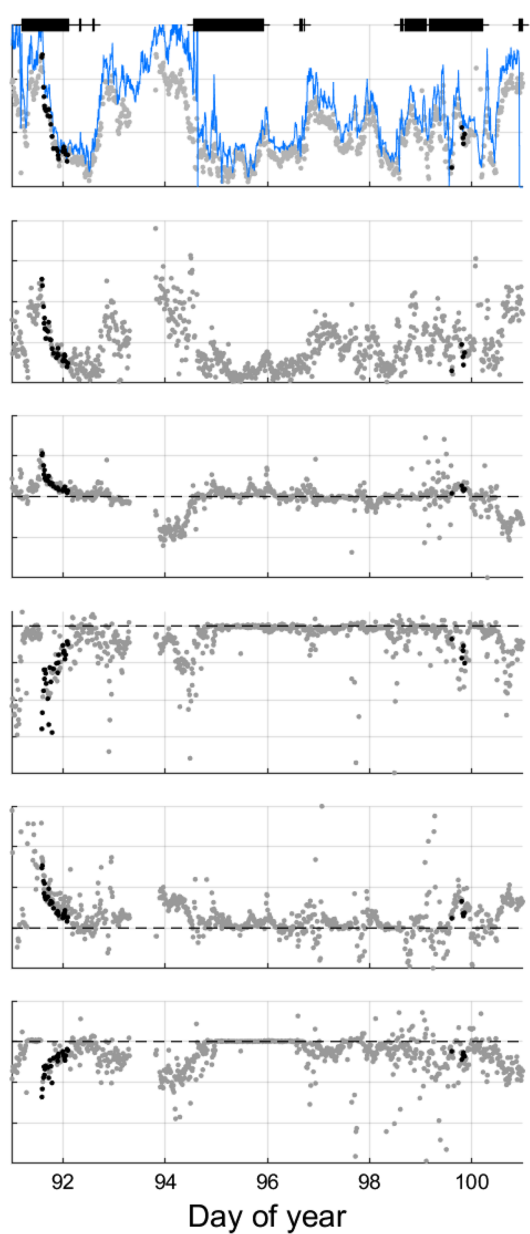
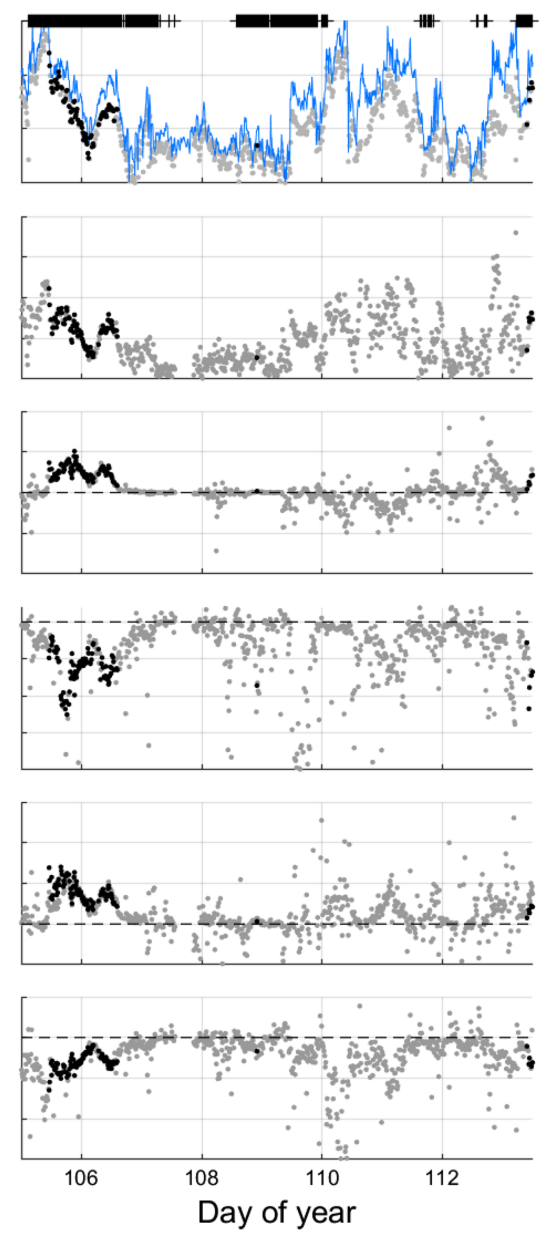

Figure 1. Time series observations from the FRF pier in Duck, North Carolina. For all panels—black points: intervals when $k_{m o m}, k_{\mathrm{H}_{2} \mathrm{O}}$, and $k_{\mathrm{SO}_{2}}$ passed all quality control; gray points: intervals with data failing one or more quality control criteria. From top: (1) wind speed measured on the eddy covariance boom, “+” symbols across the top indicate intervals when winds were in-sector (on shore); blue line: FRF tower anemometer (30 m above mean sea level), (2) friction velocity calculated from observed momentum flux, (3) water vapor air/sea flux $\left(F_{\mathrm{H}_{2} \mathrm{O}}\right)$, (4) sulfur dioxide air/sea flux $\left(F_{\mathrm{H}_{2} \mathrm{O}}\right),(5)$ water vapor gas transfer velocity $\left(k_{\mathrm{H}_{2} \mathrm{O}}\right)$, and (6) sulfur dioxide gas transfer velocity $\left(k_{\mathrm{SO}_{2}}\right)$. Time axis is in UTC.

The Duck field data are compared to three gas transfer parameterizations, which estimate the combined resistance from (1) the interfacial region where molecular diffusion and viscosity are important and the velocity profile is linear and (2) the overlying turbulent layer where eddy diffusion dominates and the velocity profile is logarithmic. This is described simply as

$$
k_{a_{-} \text {total }}{ }^{-1}=r_{a_{\_} \text {total }}=r_{a_{-} \text {interfacial }}+r_{a_{-} \text {turbulent }} .
$$

For smooth flow (smooth rigid wall or low wind speeds over a water surface) the velocity profile and resistance is well constrained by laboratory measurements (Riley et al., 1982; van Driest, 1956). In the rough flow regime, the velocity profile above a water surface is much more complex, and there is a lack of laboratory data for wind/wave conditions relevant to the ocean. The bulk parameterizations used here are from Duce et al. (1991; denoted as D1991), Fairall et al. (2000, 2011, COAREG 3.6), and Donelan and Soloviev (2016; denoted as DS2016).

The gas transfer models used here all exhibit near linear relationships between gas transfer velocities and friction velocity. For both water vapor and sulfur dioxide, the models exhibit a stronger dependence on wind stress than the observations. For water vapor, the model $k / u^{*}$ slopes are 25\% (DS2016) and 50\% (COAREG 3.6, D1991) larger than the observations. The models match the $\mathrm{H}_{2} \mathrm{O}$ observations well at intermediate 

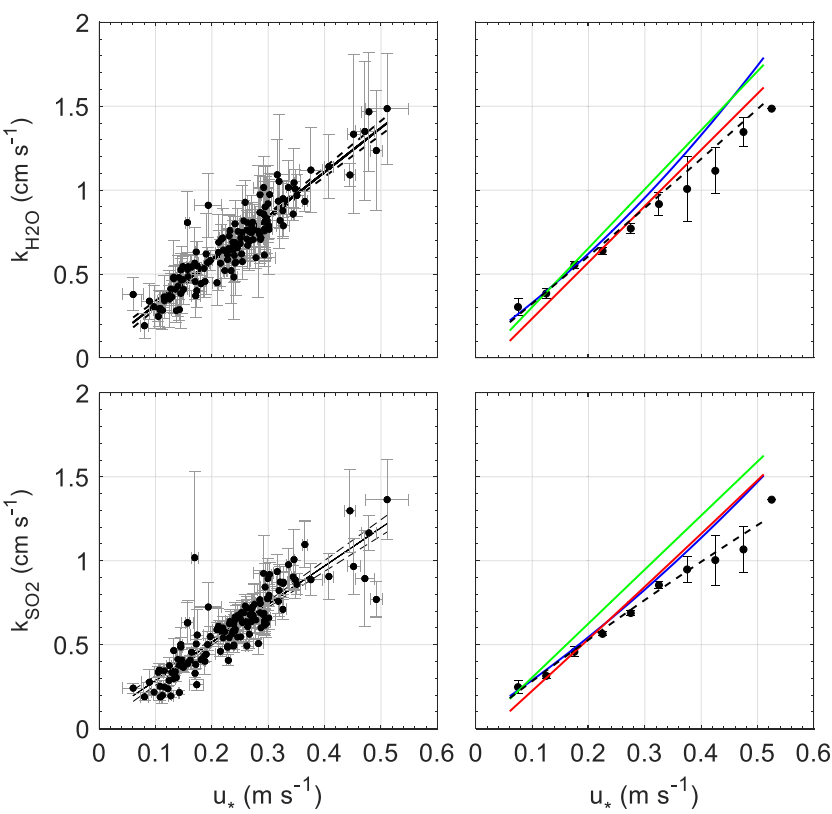

Figure 2. Simultaneous observations of gas transfer velocities as a function of friction velocity at the Duck pier, compared to several bulk gas transfer parameterizations. All measurements were made during onshore airflow. Upper row: water vapor; bottom row: sulfur dioxide. Left plots: individual flux intervals with linear regression showing $95 \%$ confidence bounds (dashed line). Right plots: the same data bin-averaged by friction velocity in $0.05 \mathrm{~m} / \mathrm{s}$ bins. The colored lines are from several air/sea gas transfer models, as follows (see text for abbreviations): COAREG 3.6 (blue), DS2016 (red), and D1991 (green). The dashed black line is a wave-modified version of the COAREG 3.6 using only $u *$ tangential to compute the air side interfacial resistance. winds but are biased low at low winds and high at high winds (Figure 2). For $\mathrm{SO}_{2}$, the model slopes are greater than the observed slope by $30 \%$ (COAREG 3.6 and DS2016) and 60\% (D1991). All of the models are in general agreement with the observed $k_{\mathrm{SO}_{2}}$ at low winds but overestimate the observations at intermediate and higher winds. Although the high wind speed data in this study are limited, the results appear to indicate that the $k_{\mathrm{SO}_{2}}$ and $k_{\mathrm{H}_{2} \mathrm{O}}$ are lower than expected at $u_{*} \geq 0.3 \mathrm{~m} / \mathrm{s}$, or wind speeds above about $7 \mathrm{~m} / \mathrm{s}$.

Although the current models do not predict nonlinearity in the relationship between gas transfer velocity and wind stress for air-side controlled gases, there are physical reasons why it might occur. The mechanisms by which momentum is transferred to the sea surface change dramatically as a function of wind speed and sea state. Viscous (sometimes referred to as tangential) surface stress predominates at low wind speeds, and form drag becomes dominant at intermediate and high wind speeds. Momentum is also transferred by wave breaking, and associated airflow separation can lead to sheltering of the wave troughs. The total stress at the surface has been described as the sum of viscous, wave-induced, and airflow separation components (Kudryavtsev \& Makin, 2007; Mueller \& Veron, 2008; Reul et al., 1999).

Wind-wave effects have long been recognized as a strong influence on the drag coefficient (Donelan \& Soloviev, 2016) but have only recently received attention in gas transfer. Wind-wave effects were suggested to explain recent observations of suppressed gas transfer of dimethylsulfide at intermediate to high wind speeds (Bell et al., 2013; Bell et al., 2015; Blomquist et al., 2017; Brumer et al., 2017; Yang et al., 2011; Zavarsky et al., 2018). To simulate those effects, the COAREG 3.6 model was modified to partition surface stress between viscous and wave-induced components in calculating water-side gas transfer resistance (Fairall et al., 2011; Yang et al., 2011). COAREG 3.6 follows Mueller and Veron (2008) in computing viscous stress as equivalent to the smooth flow limit, where roughness length, $z_{0}=0.11 v / u_{*}$ tangential. Here we apply the same partitioning to the wind stress in the calculation of air-side resistance, as follows:

$$
\begin{gathered}
r_{a \_ \text {interfacial }}=\frac{1}{u_{\text {*tangential }}} 13.3^{*} S c^{\frac{1}{2}}, \\
r_{a \_ \text {turbulent }}=\frac{1}{u_{*}^{*} \text { total }}\left[C_{d}^{-1 / 2}+\frac{0.5 * \log [S c]}{0.4}-5\right], \\
k_{a \_ \text {interfacial }}=\left(r_{a \_ \text {interfacial }}+r_{a_{-} \text {turbulent }}\right)^{-1},
\end{gathered}
$$

where $S c$ is Schmidt number. This approach greatly oversimplifies the complex dynamics of wind-wave interactions (e.g., Yang and Shen, 2017), but it illustrates how waves might alter the linearity of the wind speed dependence of soluble gas deposition. The wave-modified COAREG 3.6 model shows the expected effect, which the wind speed-dependence of air-side resistance decreases with increasing wind speeds, which simulates the general character of the Duck data set better than the other models, with lower RMS errors for both the individual observations and the bin-averaged data (Figure 2; Table S1). With more detailed field measurements of wave properties, this simplified approach could be extended by explicitly incorporating flow separation and wave sheltering, which might further suppress viscous stress.

\subsection{Sc-Number Dependence of Air-Side Resistance}

Gas transfer across water surfaces scales as $S c^{-n}$, where $n$ lies in the range from 0.67 for smooth surfaces at very low wind speeds to 0.5 for transitional and rough conditions (Jahne et al., 1987; Richter \& Jahne, 2011). These values are based on gas transfer theory and laboratory studies of water-side controlled gases with 

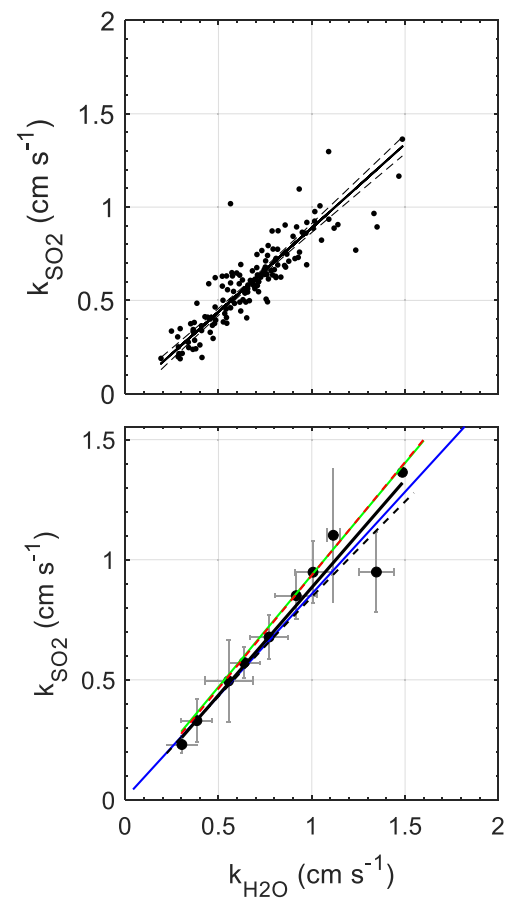

Figure 3. Gas transfer velocities of $\mathrm{SO}_{2}$ and $\mathrm{H}_{2} \mathrm{O}$ from simultaneous observations at the Duck pier during onshore airflow and neutral to unstable conditions, compared to gas transfer models. Upper: field observations. Lower: gas transfer velocities (mean $\pm 1 \sigma$ ) bin averaged by $u *$ in $0.05 \mathrm{~m} / \mathrm{s}$ bins. The black lines on both plots are total (two-way) linear regressions, with dashed upper and lower $95 \%$ confidence bounds.

The colored lines are from air/sea gas transfer models, as follows (see text for abbreviations): COAREG 3.6 (blue), DS2016 (red dashed), and D1991 (green). The dashed black line is a wave-modified version of the COAREG 3.6 using only $u_{* \text { tangential }}$ to compute the air side interfacial resistance. lower solubilities and much larger $S c$ than the gases studied here. Nightingale et al. (2000) conducted the only oceanic field study of $n$ using water-side controlled gases, reporting a value of $0.51_{-0.14}^{+0.19}$.

$\mathrm{Sc}_{\mathrm{SO}_{2}}$ in air is roughly twice that of $\mathrm{H}_{2} \mathrm{O}\left(\mathrm{Sc}_{\mathrm{H}_{2} \mathrm{O}}=0.61, \mathrm{Sc}_{\mathrm{SO}_{2}}=1.19\right.$ at $\left.298 \mathrm{~K}\right)$ (Fuller et al., 1966; Hilsenrath, 1960). Simultaneous measurements of gas transfer velocities for water vapor and $\mathrm{SO}_{2}$ therefore have the potential to constrain the $S c$ dependence of soluble gas transfer under field conditions. A total least squares regression of $k_{\mathrm{SO}_{2}}$ against $k_{\mathrm{H}_{2} \mathrm{O}}$ for the Duck data set yields a slope of $0.81 \pm 0.04$ ( 1 std. err.; Figure 3). A previous study at Scripps pier yielded a $0.62 \pm 0.24$, with considerably larger uncertainty due to the limited size and wind speed range of those data (Porter et al., 2018). The Duck results are at the lower end of the range of $0.85-0.95$ predicted by the gas transfer models introduced above.

The observed $k_{\mathrm{SO}_{2}} / k_{\mathrm{H}_{2} \mathrm{O}}$ can be used to calculate an overall or "effective" $S c$ dependence. For soluble gases, the observed $S c$ dependence reflects the combined contributions of resistance in the viscous interfacial sublayer and in the overlying turbulent surface layer. The turbulent (or aerodynamic) resistance is a significant component of the total resistance for soluble gases and is assumed to have no dependence on Sc. Consequently, the effective $S c$ dependence for soluble gases should be considerably smaller than that for water-side controlled gases where almost all of the resistance is located within the interfacial sublayer.

The effective $S c$ dependence, denoted as $m$ (to differentiate from $n$, the $S c$ dependence of the interfacial sublayer itself), is calculated as follows:

$$
\frac{k_{\mathrm{SO}_{2}} / u_{*}}{k_{\mathrm{H}_{2} \mathrm{O}} / u_{*}}=\left(\frac{S c_{\mathrm{SO}_{2}}}{S c_{\mathrm{H}_{2} \mathrm{O}}}\right)^{-m} .
$$

Substituting the regression slope of $k_{\mathrm{SO} 2}$ against $k_{\mathrm{H} 2 \mathrm{O}}$ (Figure 3),

$$
0.81 \pm 0.04=\left(\frac{1.19}{0.61}\right)^{-m}
$$

which yields $m=0.32 \pm 0.07$ (neglecting uncertainty in the diffusivities). The gas transfer models examined here (D91, COAREG, and DS16) predict slightly lower values of $m$, ranging from 0.08-0.24 (Figure 2). The mismatch implies that these models underestimate either (1) the fraction of total resistance in the interfacial sublayer compared to the turbulent layer (as discussed earlier) or (2) the $S c$ dependence $(n)$ of transport across the interfacial sublayer. The wave-modified COAREG model exhibits wind speed dependence in $m$ ranging from $0.29-0.36$ for $u_{*}$ ranging from $0.2-0.5 \mathrm{~m} / \mathrm{s}$. The Duck field data are insufficient to determine if the $S c$ dependence varies with $u_{*}$. Lab studies suggest that the transition of $\mathrm{n}$ from smooth to rough values occurs over a broad range of $u_{*}$ and is sensitive to surfactants (Nagel et al., 2019; Richter \& Jahne, 2011).

This study provides a field-based estimate of the dependence of air-side resistance on molecular diffusivity. Earlier studies obtained a similar trend in Sc dependence for air/sea transfer of sensible heat and methanol ( $S c=0.64$ and 1.09, respectively; Yang et al., 2013; 2014). Those results are dependent on the assumption that sea surface methanol levels were negligible, in spite of the presence in the underlying bulk seawater.

\section{Conclusions}

This study presents simultaneous eddy covariance air-sea flux measurements of water vapor and sulfur dioxide in a coastal environment. The data show that the gas transfer velocity for $\mathrm{SO}_{2}$ is less than that for $\mathrm{H}_{2} \mathrm{O}$, as expected because of diffusive resistance to gas transfer in the interfacial layer just above the sea surface. The 
Acknowledgments

The authors wish to thank Kent Hathaway and the staff at the USACE Federal Research Facility at Duck, North Carolina, for their support in conducting this research. We also wish to thank Keqi Tang at Pacific Northwest National Laboratory for assistance in the design and construction of the ion funnel used in this study. Cyril McCormick of the UCI Instrumentation Development Facility provided field and laboratory support for this project. Funding for this research was provided by NASA (Grant NNX15AF31G) and the NSF IR/D program. Data used in this study are available online (at the following openaccess archives: https://dash.lib.uci. edu/stash/dataset/doi:10.7280/ D1Z39F, https://www.ndbc.noaa.gov and http://frf.usace.army.mil/frf_data. shtml)
Duck field study confirms previous limited field observations at Scripps pier (Porter et al., 2018). The results are in qualitative agreement with gas transfer theory and bulk parameterizations of gas transfer of highly soluble gases. Quantitatively, the field data exhibit an Sc number dependence slightly greater than predicted by the models. The data also provide intriguing preliminary evidence for nonlinearity in the relationship between the gas transfer velocities and friction velocity, which we speculate results from wind-wave interactions. This study highlights the potential for simultaneous eddy covariance flux measurements of multiple highly soluble compounds to provide new insights into mass transfer across the air side of the airsea interface.

\section{References}

Andreas, E. (2005). Handbook of physical constants and functions for use in atmospheric boundary layer studies (US Army Corps of Engineers No. ERDC/CRREL M-05-1) (p. 54).

Bell, T. G., De Bruyn, W., Marandino, C. A., Miller, S. D., Law, C. S., Smith, M. J., \& Saltzman, E. S. (2015). Dimethylsulfide gas transfer coefficients from algal blooms in the Southern Ocean. Atmospheric Chemistry and Physics, 15(4), 1783-1794. https://doi.org/10.5194/ acp-15-1783-2015

Bell, T. G., De Bruyn, W., Miller, S. D., Ward, B., Christensen, K. H., \& Saltzman, E. S. (2013). Air-sea dimethylsulfide (DMS) gas transfer in the North Atlantic: Evidence for limited interfacial gas exchange at high wind speed. Atmospheric Chemistry and Physics, 13(21), 11,073-11,087. https://doi.org/10.5194/acp-13-11073-2013

Blomquist, B. W., Brumer, S. E., Fairall, C. W., Huebert, B. J., Zappa, C. J., Brooks, I. M., et al. (2017). Wind speed and sea state dependencies of air-sea gas transfer: Results from the high wind speed gas exchange study (HiWinGS). Journal of Geophysical Research, Oceans, 122(10), 8034-8062. https://doi.org/10.1002/2017JC013181

Brown, J. M., Amoudry, L. O., Mercier, F. M., \& Souza, A. J. (2013). Intercomparison of the Charnock and COARE bulk wind stress formulations for coastal ocean modelling. Ocean Science, 9(4), 721-729. https://doi.org/10.5194/os-9-721-2013

Brumer, S. E., Zappa, C. J., Blomquist, B. W., Fairall, C. W., Cifuentes-Lorenzen, A., Edson, J. B., et al. (2017). Wave-related Reynolds number parameterizations of $\mathrm{CO}_{2}$ and DMS transfer velocities. Geophysical Research Letters, 44(19), 9865-9875. https://doi.org/10.1002/ 2017GL074979

Callaghan, A. H., \& White, M. (2009). Automated processing of sea surface images for the determination of whitecap coverage. Journal of Atmospheric and Oceanic Technology, 26(2), 383-394. https://doi.org/10.1175/2008JTECHO634.1

Donelan, M. A., \& Soloviev, A. V. (2016). A mixing length model for the aqueous boundary layer including the effect of wave breaking on enhancing gas transfer. IOP Conference Series: Earth and Environmental Science, 35(1), 012001.

Duce, R. A., Liss, P. S., Merrill, J. T., Atlas, E. L., Buat-Menard, P., Hicks, B. B., et al. (1991). The atmospheric input of trace species to the world ocean. Global Biogeochemical Cycles, 5(3), 193-259. https://doi.org/10.1029/91GB01778

Fairall, C. W., Hare, J. E., Edson, J. B., \& McGillis, W. (2000). Parameterization and micrometeorological measurement of air-sea gas transfer. Boundary-Layer Meteorology, 96(1), 63-106. https://doi.org/10.1023/A:1002662826020

Fairall, C. W., Yang, M., Bariteau, L., Edson, J. B., Helmig, D., McGillis, W., et al. (2011). Implementation of the Coupled OceanAtmosphere Response Experiment flux algorithm with $\mathrm{CO}_{2}$, dimethyl sulfide, and $\mathrm{O}_{3}$. Journal of Geophysical Research, Oceans, 116(C4) https://doi.org/10.1029/2010JC006884

Faloona, I., Conley, S. A., Blomquist, B., Clarke, A. D., Kapustin, V., Howell, S., et al. (2009). Sulfur dioxide in the tropical marine boundary layer: Dry deposition and heterogeneous oxidation observed during the Pacific Atmospheric Sulfur Experiment. Journal of Atmospheric Chemistry, 63(1), 13-32. https://doi.org/10.1007/s10874-010-9155-0

Fuller, E. N., Schettler, P. D., \& Giddings, J. C. (1966). New method for prediction of binary gas-phase diffusion coefficients. Industrial and Engineering Chemistry, 58(5), 18-27. https://doi.org/10.1021/ie50677a007

Garratt, J. R., \& Hicks, B. B. (1973). Momentum, heat and water vapour transfer to and from natural and artificial surfaces. Quarterly Journal of the Royal Meteorological Society, 99(422), 680-687. https://doi.org/10.1002/qj.49709942209

Geernaert, G. L., Katsaros, K. B., \& Richter, K. (1986). Variation of the drag coefficient and its dependence on sea state. Journal of Geophysical Research, Oceans, 91(C6), 7667-7679. https://doi.org/10.1029/JC091iC06p07667

Grachev, A. A., Leo, L. S., Fernando, H. J. S., Fairall, C. W., Creegan, E., Blomquist, B. W., et al. (2017). Air-Sea/Land Interaction in the Coastal Zone. Boundary-Layer Meteorology. https://doi.org/10.1007/s10546-017-0326-2

Hicks, B. B., \& Liss, P. S. (1976). Transfer of $\mathrm{SO}_{2}$ and other reactive gases across the air-sea interface. Tellus, 28(4), 348-354. https://doi.org/ 10.1111/j.2153-3490.1976.tb00683.x

Hilsenrath, J. (1960). Tables of thermodynamic and transport properties of air, argon, carbon dioxide, carbon monoxide, hydrogen, nitrogen, oxygen, and steam. Oxford, U.K: Pergamon Press.

Jahne, B., Munnich, K. O., Bosinger, R., Dutzi, A., Huber, W., \& Libner, P. (1987). On the parameters influencing air-water gas exchange. Journal of Geophysical Research: Oceans, 92(C2), 1937-1949. https://doi.org/10.1029/JC092iC02p01937

Joffre, S. M. (1988). Modelling the dry deposition velocity of highly soluble gases to the sea surface. Atmospheric Environment (1967), 22(6), 1137-1146. https://doi.org/10.1016/0004-6981(88)90343-5

Johnson, M. T. (2010). A numerical scheme to calculate temperature and salinity dependent air-water transfer velocities for any gas. Ocean Science, 6(4), 913-932. https://doi.org/10.5194/os-6-913-2010

Kaimal, J. C., Wyngaard, J. C., Izumi, Y., \& Coté, O. R. (1972). Spectral characteristics of surface-layer turbulence. Quarterly Journal of the Royal Meteorological Society, 98(417), 563-589. https://doi.org/10.1002/qj.49709841707

Kramm, G., \& Dlugi, R. (1994). Modelling of the vertical fluxes of nitric acid, ammonia, and ammonium nitrate. Journal of Atmospheric Chemistry, 18(4), 319-357.

Kudryavtsev, V. N., \& Makin, V. K. (2007). Aerodynamic roughness of the sea surface at high winds. Boundary-Layer Meteorology, 125(2), 289-303. https://doi.org/10.1007/s10546-007-9184-7

Liss, P. (1971). Exchange of $\mathrm{SO}_{2}$ between the atmosphere and natural waters. Nature, 233(5318), 327-329. https://doi.org/doi:10.1038/ 233327a0

Liss, P., \& Slater, P. G. (1974). Flux of gases across the air-sea interface. Nature, 247, 181-184. 
Liu, W. T., Katsaros, K. B., \& Businger, J. A. (1979). Bulk parameterization of air-sea exchanges of heat and water vapor including the molecular constraints at the interface. Journal of the Atmospheric Sciences, 36(9), 1722-1735. https://doi.org/10.1175/1520-0469 (1979)036<1722:BPOASE > 2.0.CO;2

Marandino, C. A., De Bruyn, W. J., Miller, S. D., Prather, M. J., \& Saltzman, E. S. (2005). Oceanic uptake and the global atmospheric acetone budget. Geophysical Research Letters, 32(15). https://doi.org/10.1029/2005GL023285

Millero, F. J., Hershey, J. B., Johnson, G., \& Zhang, J.-Z. (1989). The solubility of $\mathrm{SO}_{2}$ and the dissociation of $\mathrm{H}_{2} \mathrm{SO}_{3}$ in $\mathrm{NaCl}_{\text {solutions }}$ Journal of Atmospheric Chemistry, 8(4), 377-389. https://doi.org/10.1007/BF00052711

Möhler, O., Reiner, T., \& Arnold, F. (1992). The formation of $\mathrm{SO}_{5}{ }^{-}$by gas phase ion-molecule reactions. The Journal of Chemical Physics, 97(11), 8233-8239. https://doi.org/10.1063/1.463394

Mueller, J. A., \& Veron, F. (2008). Nonlinear formulation of the bulk surface stress over breaking waves: Feedback mechanisms from airflow separation. Boundary-Layer Meteorology, 130(1), 117-134. https://doi.org/10.1007/s10546-008-9334-6

Nagel, L., Krall, K. E., \& Jähne, B. (2019). Measurements of air-sea gas transfer velocities in the Baltic Sea. Ocean Science, 15(2), 235-247. https://doi.org/10.5194/os-15-235-2019

Nightingale, P. D., Malin, G., Law, C. S., Watson, A. J., Liss, P. S., Liddicoat, M. I., et al. (2000). In situ evaluation of air-sea gas exchange parameterizations using novel conservative and volatile tracers. Global Biogeochemical Cycles, 14(1), 373-387. https://doi.org/10.1029/ 1999GB900091

Porter, J. G., De Bruyn, W., \& Saltzman, E. S. (2018). Eddy flux measurements of sulfur dioxide deposition to the sea surface. Atmospheric Chemistry and Physics, 18(20), 15,291-15,305. https://doi.org/10.5194/acp-18-15291-2018

Reid, R. C., Prausnitz, J. M., \& Poling, B. E. (1987). The properties of gases of liquids: Their estimation and correlation (4th ed.). New York, USA: McGraw-Hill.

Reul, N., Branger, H., \& Giovanangeli, J.-P. (1999). Air flow separation over unsteady breaking waves. Physics of Fluids, 11(7), 1959-1961. https://doi.org/10.1063/1.870058

Richter, K., \& Jahne, B. (2011). A laboratory study of the Schmidt number dependency of air-water gas transfer. In In Gas Transfer at Water Surfaces 2010 (pp. 322-332). Kyoto, Japan: Kyoto University Press. https://doi:10.5281/zenodo.14955

Riley, D. S., Donelan, M. A., \& Hui, W. H. (1982). An extended Miles' theory for wave generation by wind. Boundary-Layer Meteorology, 22(2), 209-225. https://doi.org/10.1007/BF00118254

Sheng, J.-X., Weisenstein, D. K., Luo, B.-P., Rozanov, E., Stenke, A., Anet, J., et al. (2015). Global atmospheric sulfur budget under volcanically quiescent conditions: Aerosol-chemistry-climate model predictions and validation. Journal of Geophysical Research-Atmospheres, 120(1), 256-276. https://doi.org/10.1002/2014JD021985

Slinn, W. G. N., Hasse, L., Hicks, B. B., Hogan, A. W., Lal, D., Liss, P. S., et al. (1978). Some aspects of the transfer of atmospheric trace constituents past the air-sea interface. Atmospheric Environment (1967), 12(11), 2055-2087. https://doi.org/10.1016/0004-6981(78) 90163-4

Smith, S. D. (1988). Coefficients for sea surface wind stress, heat flux, and wind profiles as a function of wind speed and temperature. Journal of Geophysical Research, Oceans, 93(C12), 15,467-15,472. https://doi.org/10.1029/JC093iC12p15467

Thornton, D. C., Bandy, A. R., Tu, F. H., Blomquist, B. W., Mitchell, G. M., Nadler, W., \& Lenschow, D. H. (2002). Fast airborne sulfur dioxide measurements by Atmospheric Pressure Ionization Mass Spectrometry (APIMS). Journal of Geophysical Research-Atmospheres, 107(D22), ACH), 13-11. https://doi.org/10.1029/2002JD002289

van Driest, E. R. (1956). On turbulent flow near a wall. Journal of Aerosol Science, 23(11), 1007-1011.

Yang, M., Beale, R., Liss, P., Johnson, M., Blomquist, B., \& Nightingale, P. (2014). Air-sea fluxes of oxygenated volatile organic compounds across the Atlantic Ocean. Atmospheric Chemistry and Physics, 14(14), 7499-7517. https://doi.org/10.5194/acp-14-7499-2014

Yang, M., Bell, T. G., Blomquist, B. W., Fairall, C. W., Brooks, I. M., \& Nightingale, P. D. (2016). Air-sea transfer of gas phase controlled compounds. IOP Conference Series: Earth and Environmental Science, 35, 012011. https://doi.org/10.1088/1755-1315/35/1/012011

Yang, M., Blomquist, B. W., Fairall, C. W., Archer, S. D., \& Huebert, B. J. (2011). Air-sea exchange of dimethylsulfide in the Southern Ocean: Measurements from SO GasEx compared to temperate and tropical regions. Journal of Geophysical Research, Oceans, 116(C4). https://doi.org/10.1029/2010JC006526

Yang, M., Nightingale, P. D., Beale, R., Liss, P. S., Blomquist, B., \& Fairall, C. (2013). Atmospheric deposition of methanol over the Atlantic Ocean. Proceedings of the National Academy of Sciences, 110(50), 20,034-20,039. https://doi.org/10.1073/pnas.1317840110

Zavarsky, A., Goddijn-Murphy, L., Steinhoff, T., \& Marandino, C. A. (2018). Bubble-mediated gas transfer and gas transfer suppression of DMS and $\mathrm{CO}_{2}$. Journal of Geophysical Research-Atmospheres, 123(12), 6624-6647. https://doi.org/10.1029/2017JD028071 